\title{
O direito à educação na perspectiva da pedagogia histórico- crítica e a educação especial
}

The right to education from the perspective of historical-critical pedagogy and special education

El derecho a la educación desde la perspectiva de la pedagogía históricocrítica y la educación especial

\section{Adriana Cristina Morais Eloy}

Mestra pela Universidade Federal de São Carlos, Sorocaba, São Paulo, Brasil.

adricmorais@hotmail.com

ORCID - http://orcid.org/0000-0002-4512-0853

\section{Luciana Cristina Salvatti Coutinho}

Professora doutora na Universidade Federal de São Carlos, Sorocaba, São Paulo, Brasil lucscoutinho@gmail.com

ORCID - http://orcid.org/0000-0002-8682-0952

Recebido em 16 de novembro 2019

Aprovado em 2 de agosto de 2020

Publicado em 30 de setembro de 2020

\section{RESUMO}

Esse artigo insere-se o debate sobre o direito à educação dos alunos com deficiência atendidos na escola comum, a perspectiva da pedagogia histórico-crítica, cuja base é o materialismo histórico-dialético. Utilizando procedimentos de análise bibliográfica e documental (legislação), empreende-se uma reflexão histórico-educacional. A história da educação no Brasil evidencia um atendimento elitizado em detrimento daqueles que viviam (e vivem) do trabalho braçal. Na esteira da educação normalizada também se percebe, na história da educação especial, o início do acesso àqueles que pertenciam à elite. É somente na Constituição Federal de 1988 que se preconiza, no Brasil, a educação como direito, fruto de movimentos de lutas sociais, incluindo, aqui, os das pessoas com deficiência. Tendo como base o conceito de humanização, defende-se que o direito à educação, para ser efetivado, precisa garantir condições plenas de acesso às pessoas e às pessoas com deficiência à escolarização, entendida como o processo de transmissão-apropriação dos conhecimentos sistematizados histórica e coletivamente pela humanidade.

Palavras-chave: Pedagogia histórico-crítica; Educação Especial; Escolarização.

\section{ABSTRACT}

This article inserts in a debate about Education Rights to students with disabilities attended in a common, school in historical- critical pedagogy, which is based in dialectical materialism. Using bibliographic and documentary analysis procedures (legislation), there is a historical-educational reflex. The history of Education in Brazil shows an elite service at the detriment of those who lived (and live) of manual labor. In the stream of normalized Education, the beginning of access to those who belonged to the elite can also be seen in the History of Special Education. It is only in the Federal Constitution of 1988 that Education as a right is advocated in Brazil, as a result of social movements, including, here, people 
http://dx.doi.org/10.5902/1984686X41161

with disabilities. Based on the concept of humanization, it is argued that the right to Education, to be effective, needs to guarantee full conditions of access to people and people with disabilities to schooling, understood as the process of transmission-appropriation of systematized knowledge, historically and collectively for humanity.

Keywords: Historical-critical pedagogy; Special Education; Schooling.

\section{RESUMEN}

Este artículo insiere se en el debate sobre el derecho a la educación de los alumnos con discapacidad asistidos en la escuela común en la perspectiva de la pedagogía históricocritica, cuya base es el materialismo histórico-dialectico. Mediante procesos de análisis bibliográfico y documental (legislación), se realiza un reflejo histórico-educacional. La historia de la educación en Brasil muestra un servicio de élite en detrimento de quienes vivieron (y viven) del trabajo manual. A raíz de la educación normalizada, el inicio del acceso a quienes pertenecían a la élite también se puede ver en la historia de la educación especial. Solo en la Constitución Federal de 1988 se defiende la educación como un derecho en Brasil, resultado de movimientos de luchas sociales, incluidas aquí, las de las personas con discapacidad. Partiendo del concepto de humanización, se argumenta que el derecho a la educación, para ser efectivo, se necesita garantizar plenas condiciones de acceso a la escolarización de las personas y personas con discapacidad, entendido como el proceso de transmisión- apropiación de conocimientos sistematizados, históricamente colectivamente para la humanidad.

Palabras clave: Pedagogía histórico-critica; Educación Especial; Escolarización.

\section{Introdução}

Nesse artigo busca-se refletir sobre o direito à educação, de modo geral e, especificamente, em relação às pessoas com deficiência. Embora inscrito no corpo legal, nota-se que esse direito, quando referido às pessoas público-alvo da educação especial ${ }^{1}$ ainda caminha por tortuosos e pouco delineados processos ${ }^{2}$.

No transcorrer da história, de acordo com Jannuzzi (2012), desde os tempos remotos, a escola sempre foi pensada para uma elite, sendo favorecido o trabalho intelectual e para a classe trabalhadora, o trabalho braçal, portanto, não carecendo de instrução. Em referência às pessoas com deficiência, houve uma invisibilidade em relação à escolarização tanto pelas legislações quanto pelas práticas de socialização.

A história da educação especial, assim, tal como analisam Godofredo (2007), Jannuzzi (2012) e Teixeira (2008), é fortemente marcada pela exclusão, segregação, tentativas de integração e, mais recentemente, pela defesa da educação inclusiva.

A educação inclusiva, contudo, apesar dos avanços relativos à matrícula de alunos com deficiência, ainda precisa avançar em relação às mudanças estruturais que dizem respeito à formação do professor, à acessibilidade (transporte especial, prédios adaptados, 
materiais pedagógicos de acordo com a necessidade e especificidade de cada deficiência e/ou transtorno, considerando as peculiaridades referentes ao seu modo de aprender), como também ao ensino que promova apropriação dos conhecimentos sistematizados na forma de saber escolar.

Em relação à formação do professor, Sousa (2018, p. 45-46) afirma que:

a questão da Formação de Professor não pode ser dissociada de alguns fatores, tais como as condições precárias de trabalho, os salários aviltantes e a jornada de trabalho excessiva a que se submetem para compensar os baixos salários. Tudo isso é fato na vida dos professores. Além do que, esses fatores causam anomia social, dificultando a formação continuada com qualidade.

Destarte, os elementos supracitados, pertencentes à estrutura necessária para a efetivação do ensino, possibilitariam condições materiais e não-materiais para o aprendizado e desenvolvimento de todos(as) os(as) alunos(as), independentemente de suas condições biofísicas, psíquicas, sociais.

Apoiando-se em autores alinhados à pedagogia histórico-crítica (PHC), tais como Barroco (2011), Duarte (2004, 2016), Martins (2013a, 2013b, 2017), Saviani (2013a, 2013b, 2015), Caiado e Jannuzzi (2013) e Martins, Lavoura e Marsiglia (2019), busca-se referendar a socialização dos conhecimentos científicos, filosóficos, artísticos e éticos elaborados na cultura dos homens, transformados em saberes escolares, trazendo para o texto a discussão sobre a necessidade de atribuir sentido pedagógico ao direito à educação, de modo geral, relacionando-o ao atendimento do público-alvo da educação especial.

Para a PHC, o acesso ao conhecimento sistematizado dá-se por meio do trabalho educativo, que, de acordo com Saviani (2013a, p. 13), refere-se ao "ato de produzir, direta e intencionalmente, em cada indivíduo singular, a humanidade que é produzida histórica e coletivamente pelo conjunto dos homens". Desta maneira, é possível oportunizar o acesso à cultura, que são os bens materiais e não materiais produzidos através da atividade consciente e intencional, sendo, portanto, a síntese da atividade humana objetivada (DUARTE, 2004). Essa apropriação oportuniza aos seres humanos os instrumentos analíticos que thes permitem a leitura do mundo em que estão inseridos, propiciando, assim, melhores condições de inserção social de forma consciente e eficaz.

Assim sendo, o acesso à escolarização dos alunos público-alvo da educação especial faz-se necessário, pois vivemos numa cultura letrada, simbolicamente representada nas diferentes formas de expressão dos saberes teóricos e práticos, como objetivações construídas historicamente pelos homens que sintetizam, portanto, a atividade humana ao 
http://dx.doi.org/10.5902/1984686X41161

longo do tempo e do espaço. Essa forma que a cultura assume na contemporaneidade exige a apropriação de instrumentos elementares que possibilitem o acesso ao conjunto dos conhecimentos. Um desses conhecimentos elementares, base para saltos qualitativos no processo de desenvolvimento e aprendizagem, é a apropriação do sistema de escrita alfabético, que só é possível por meio de um trabalho educativo intencional e sistematicamente organizado.

Logo, ao apoiar-se na pedagogia histórico-crítica para refletir sobre as possibilidades para efetivação do direito à educação, busca-se evidenciar que, para além de estar no ambiente escolar com condições de acessibilidade, é preciso possibilitar acesso, na escola, aos instrumentos culturais historicamente produzidos entendidos como alavancadores do desenvolvimento humano em sua multidimensionalidade.

Isso porque, numa sociedade letrada, esses instrumentos culturais, sendo essenciais, tornam-se clássicos, no sentido atribuído por Saviani (2013a, p. 13), para quem

O clássico não se confunde com o tradicional e também não se opõe, necessariamente, ao moderno e muito menos ao atual. O clássico é aquilo que se firmou como fundamental, como essencial. Pode, pois, constituir-se num critério útil para a seleção dos conteúdos do trabalho pedagógico.

Desta maneira, este artigo insere-se no debate sobre o sentido atribuído ao direito à educação, buscando subsídios que corroborem na garantia desse direito a todos(as), mas, sobretudo, aos alunos público-alvo da educação especial.

Fundamentando-se no materialismo histórico-dialético, referência para a pedagogia histórico-crítica, entende-se que a educação e a educação das pessoas com deficiência são fenômenos histórico-sociais intrinsecamente articulados e acompanham a história da humanidade, adquirindo características específicas de acordo com as mudanças ocorridas nos diferentes tempos e contextos. Empreendeu-se, assim, uma reflexão históricoeducacional, utilizando-se de análises bibliográfica e documental (legislação).

O artigo está estruturado em três tópicos que, espera-se, dêem conta dos objetivos aqui expostos, a saber: processo histórico e o direito à educação da pessoa com deficiência; educação e humanização; humanização, direito à educação e escolarização. As reflexões realizadas nesses itens são antecedidos por essa introdução e precedidos de algumas palavras a título de considerações finais. 


\section{Processo histórico e o direito à educação da pessoa com deficiência}

Sendo os alunos público-alvo da educação especial sujeitos de direitos e, como tal, com direito legítimo à educação, pode-se dizer que, no decorrer da história, estes sempre foram invisíveis diante das legislações educacionais, visto que no país do século XIX, o acesso ao ensino somente interessava e era disponibilizado à classe dominante. $\mathrm{O}$ ensino fundamental era oferecido aos filhos de quem detinha o poder e estava livre do trabalho braçal, enquanto a população sem escola estava a trabalhar no campo, já que a sociedade era pouco urbanizada. Neste momento, a preocupação ainda era o ensino superior, já que os filhos da elite precisavam ser doutores (JANUZZI, 2012, p. 15).

Jannuzzi (2012, p.15) ainda contextualiza este momento histórico da seguinte forma:

A educação popular, e muito menos a dos deficientes, não era motivo de preocupação. $\mathrm{Na}$ sociedade pouco urbanizada, apoiada no setor rural, primitivamente aparelhado, provavelmente poucos eram considerados deficientes; havia lugar, havia tarefa que muitos deles executassem. A população era iletrada na sua maior parte, as escolas eram escassas, como já foi salientado, e dado que só recorriam a ela as camadas sociais alta e média, a escola não funcionou como crivo, como elemento da patenteação de deficiências. Havia pouca divergência entre o modo de conceber o mundo que nela se difundia e o da família o qual o aluno fazia parte. Certamente só as crianças mais lesadas despertavam atenção e eram recolhidas em algumas instituições.

Neste contexto, a preocupação com a educação da população pertencente à classe trabalhadora era inexistente, estendendo-se àquelas com algum tipo de deficiência. Sendo o trabalho no campo do tipo braçal, a escolarização não provocava a pauta política daqueles que detinham o poder.

Ainda neste período (século XIX), D. Pedro II fundava, no Rio de Janeiro, o Imperial Instituto dos Meninos Cegos (1854), hoje o Instituto Benjamin Constant e o Imperial Instituto de Surdos Mudos (1857), o atual Instituto Nacional de Educação dos Surdos (INES).

Em outras palavras, a preocupação com a criação destes institutos não era com a educação da pessoa com deficiência. Porém, a intenção era fazer com que estes indivíduos fossem institucionalizados, que fossem tirados do convívio da sociedade, de modo que era prestado um serviço de assistencialismo, sendo oferecido um atendimento médico com a intenção de normalizar a condição deles tendo como referência o que era considerado padrão de normalidade, reforçando a condição de incapazes. Como afirma Goffredo (2007, p. 27), "esta postura segregacionista era marcada pelo velho ditado: longe dos olhos, longe do coração". 
http://dx.doi.org/10.5902/1984686X41161

Além disso, pesquisas (GOFFREDO, 2007; TEIXEIRA, 2008; JANNUZZI, 2012) evidenciam que somente frequentavam tais instituições pessoas próximas à corte, pois era privilégio somente das classes dominantes, visto que, na imensidão do país, instituições voltadas a este público eram praticamente inexistentes ${ }^{3}$.

Ainda na esteira da história da educação especial, "o governo da Corte, numa sociedade agrária, iletrada, assumia educar uma minoria de cegos e surdos, movido provavelmente, por forças ligadas ao poder político, sensibilizadas com esse alunado por diversos motivos, inclusive vínculos familiares" (JANNUZZI, 2012, p. 57).

É somente com a primeira Constituição Brasileira, em 1824, que é possível inferir que se inicia, juridicamente, algum debate sobre o acesso à educação a todos os cidadãos. $O$ texto constitucional disciplinou a educação no artigo 179, XXXII e XXXIII, estabelecendo a garantia do ensino primário a todos os cidadãos e sua realização, preferencialmente, pela família e pela Igreja, bem como a criação de colégios e universidades para o ensino de Ciências, Artes e Letras. Desta maneira, o caráter elitista da educação brasileira foi reforçado nessa época com a preferência que continuava sendo atribuída ao ensino superior, cujo acesso era possibilitado apenas aos membros da nobreza e da burguesia. A questão da instrução ou ensino fundamental foi relegada ao segundo plano e superada por aquela relativa à criação das universidades (TEIXEIRA, 2008) ${ }^{4}$.

Se, no primeiro período, a intenção foi institucionalizar a pessoa com deficiência, neste segundo momento, ainda sem direito específico à educação, esses indivíduos passam a ser segregados.

Somente em 1961, com a primeira Lei de Diretrizes e Bases da Educação Nacional, a Lei 4024/61, a educação das pessoas com deficiência foi posta em evidência. Tal legislação trazia a seguinte redação:

TÍTULOX

Da Educação de Excepcionais

Art. 88. A educação de excepcionais deve, no que fôr possível, enquadrar-se no sistema geral de educação, a fim de integrá-los na comunidade.

Art. 89. Tôda iniciativa privada considerada eficiente pelos conselhos estaduais de educação, e relativa à educação de excepcionais, receberá dos poderes públicos tratamento especial mediante bôlsas de estudo, empréstimos e subvenções. (BRASIL, 1961).

Apesar de figurar no texto legal, permitindo-lhes o acesso, no sistema educacional, com objetivo explícito de integrá-los à sociedade, estas pessoas continuaram sendo segregadas, já que, no artigo 89, a LDB não preconiza, de forma integral, como dever do 
http://dx.doi.org/10.5902/1984686X41161

Estado o compromisso com a educação, passando a delegá-la às instituições privadas, dando início a dualidade de sistemas educacionais e, dessa forma, de atendimento educacional. Em relação às pessoas com deficiência, essa prerrogativa legal significou a continuidade de atendimento com base em preceitos médico-terapêuticos, deixando de lado e/ou secundarizando a escolarização.

Observe-se que, desde o império até os dias atuais, o direito da pessoa com deficiência à educação é balizado por descaso e contratempos, sem um sistema de ensino que legitime, político-juridicamente e pedagogicamente, o acesso efetivo para estes indivíduos. Se analisada desde a Lei 4024/61 (Lei de Diretrizes e Bases da Educação Nacional de 1961) até as legislações atuais houve avanços, porém, voltados, em grande medida, ao acesso. Claro que se trata de um avanço histórico, mas, justamente por isso, é preciso superar os desafios contemporâneos que se colocam ao processo de ensino e aprendizagem tendo como público-alvo as pessoas com deficiência.

Uma vez que, com a publicação de legislações para garantir o caminho à escolarização, percebe-se avanços importantes no sentido de garantir o acesso à educação escolar às pessoas público-alvo da educação especial, podendo-se exemplificar com a implementação das salas de recursos multifuncionais ${ }^{5}$, a garantia do intérprete de Libras ${ }^{6}$ para as pessoas surdas matriculadas na escola comum, Porém não suficientes, para se efetivar o direito à educação, pois não são garantidas, na integralidade, todas as condições para que, de fato, propicie-se um processo de ensino e aprendizagem desenvolvente. À título de exemplo, destacam-se as limitadas condições de trabalho de professores, bem como a formação inicial e continuada desses profissionais (OLIVEIRA e VIEIRA, 2012).

Percorrendo a história da educação especial no Brasil, percebe-se que esta vai da tentativa de institucionalização em asilos, manicômios, instituições especializadas (segregação) até as tentativas de escolarização mantendo, ainda, a parceria com as instituições especializadas. Esse atendimento educacional às pessoas com deficiência tem uma marca que acompanha sua história, articulada à necessidade de desenvolvimento econômico: é necessário capacitar o deficiente para que este contribua com o ideário capitalista de produção e consumo, já que a educação formará o capital humano, o qual, agregado ao capital físico da empresa, aumentará a produtividade (JANNUZZI, 2012, p. 149). É na condição de provável adaptação ao mercado que se define uma determinada classificação de deficiência passível de ser integrada à vida social. 
http://dx.doi.org/10.5902/1984686X41161

A pessoa com deficiência precisaria, nessa lógica, adequar-se às normas sociais com base na integração, participando, assim, da vida econômica. A ideia de integração é assumida mundialmente, a partir da década de $1970^{7}$, contando com a participação da sociedade civil e entidades internacionais. Essa ideia é amplamente difundida e fundamenta, em diferentes países, regulamentações acerca do atendimento educacional às pessoas com deficiência.

Desde a década de 1990, buscando superar a abordagem integracionista, inicia-se um movimento, com forte participação das pessoas com deficiência, por educação inclusiva, preferencialmente em redes regulares de ensino, em salas comuns, não excluindo atendimentos especializados, objetivando o pleno desenvolvimento das pessoas.

No entanto, a ideia de uma educação inclusiva ainda está caminhando a passos lentos. Uma das questões a ser enfrentada pode ser assim sintetizada: na perspectiva da educação inclusiva, o que significa, do ponto de vista pedagógico, a efetivação do direito à educação? A tentativa de responder a essa pergunta passa pela reflexão sobre as relações entre educação e humanização.

\section{Educação e humanização}

"Eu costumo, às vezes, enunciar isso da seguinte forma: o dominado não se liberta se ele não vier a dominar aquilo que os dominantes dominam. Então, dominar o que os dominantes dominam é condição de libertação" (SAVIANI, 2018, p. 45). Sem dúvida, as palavras de Saviani (2018) expressam a necessidade da apropriação dos conhecimentos por parte daqueles que, historicamente, têm sido excluídos dos processos de socialização humana para que, ao tornarem-se seres humanos do seu tempo, possam inserir-se nas relações sociais de forma a tornarem-se autônomos ${ }^{7}$.

Destarte, garantir, efetivamente, o direito à educação faz-se necessário a todas as pessoas, independentemente as suas condições biofísica, psíquica, sensorial e social, já que de acordo com o autor citado, a luta pela superação da exclusão social perpassa o domínio daquilo que os dominantes dominam (dentre eles o conhecimento), condição para a autonomia dos sujeitos, ou, em outras palavras, de sua libertação.

Libertação é entendida, aqui, na acepção de Engels $^{8}$ (1979, p. 96 apud Duarte, 2016, p. 121-122), para o qual, 
http://dx.doi.org/10.5902/1984686X41161

\begin{abstract}
A liberdade, pois, é o domínio de nós próprios e da natureza exterior, baseado na consciência das necessidades naturais; como tal é, forçosamente, um produto da evolução histórica. Os primeiros homens que se levantaram do reino animal eram, em todos os pontos essenciais de suas vidas, tão pouco livres quanto os próprios animais; cada passo dado no caminho da cultura é um passo no caminho da liberdade.
\end{abstract}

Ao ter acesso à cultura, portanto, o indivíduo liberta-se. Deste modo, Duarte (2016, p. 122) também defende que:

\begin{abstract}
A liberdade é, portanto, um processo social no qual se unem objetividade e subjetividade. Os seres humanos não se tornam livres pela negação da objetividade da natureza, mas por seu conhecimento e seu domínio. Para dominar a realidade externa o ser humano precisa dominar sua atividade, que deve ser uma atividade consciente.
\end{abstract}

Ainda de acordo com este autor, uma das maneiras como pode ser entendido o conceito de liberdade é justamente a de que o gênero humano a constrói à medida que os processos sociais sejam fruto de decisões coletivas e conscientes, diferenciando-se dos processos naturais espontâneos, ou seja, à medida que se domina o objeto a ser apropriado, o indivíduo passa a ter a condição de liberdade (DUARTE, 2004, p. 47) ${ }^{10}$.

Em relação à objetividade, Duarte (2004, p. 50-51) assevera que:

Um objeto cultural, seja ele um objeto material, como por exemplo um utensílio doméstico, seja ele um objeto não-material, como uma palavra, tem uma função social, tem um significado socialmente estabelecido, ou seja, deve ser empregado de uma determinada maneira (o fato de que o objeto cultural tenha, muitas vezes, mais de uma função não altera a regra de que sua existência está necessariamente ligada à prática social). O processo de objetivação é, portanto, o processo de produção e reprodução da cultura humana (cultura material e não-material), produção e reprodução da vida em sociedade.

Para ser exato, devo acrescentar que também o processo de objetivação faz essa mediação, pois não há apropriação da cultura se não tiver ocorrido a objetivação do ser humano nos produtos culturais de sua atividade social.

Durante essa história, o instrumento vai sofrendo transformações e aperfeiçoamentos por exigência da atividade social. Portanto os produtos culturais resultantes do processo de objetivação são sempre sínteses da atividade humana. Daí que, ao se apropriar de um produto cultural, o indivíduo está se relacionando com a história social, ainda que tal relação nunca venha a ser consciente para ele, como é o caso, para a grande maioria das pessoas, da apropriação da linguagem oral.

Entendemos que esse conceito de liberdade é princípio da pedagogia histórico-crítica e fundamento para pensar o direito à educação como sendo a socialização dos conhecimentos teóricos e práticos essenciais para viver em sociedade, em um determinado tempo e espaço. Os sujeitos tornam-se livres quando passam a dominar os conhecimentos 
http://dx.doi.org/10.5902/1984686X41161

para compreender a realidade da qual fazem parte. A escola, como uma das instituições responsáveis, na atualidade, pelo desenvolvimento humano, participa desse processo de socialização, de acordo com a pedagogia histórico-crítica, tomando como objeto de ensino e aprendizagem os conhecimentos sistematizados nas diferentes áreas do saber.

Sendo assim, ser livre passa pela apropriação da cultura letrada, pois através desta será possível acessar os produtos da cultura, aqueles que são a representação da síntese das atividades humanas. Sendo a leitura e a escrita uma produção social, as mesmas trazem em seu bojo a produção humana, configurando-se como uma dessas atividades humanas e condição para acesso a outras.

Já em relação à subjetividade, Duarte (2004, p. 54-55), ao mencionar Leontiev, defende que:

\begin{abstract}
Tanto em termos cognitivos como em termos afetivos, a estrutura do psiquismo humano diferencia-se da estrutura do psiquismo animal, tal como ocorre com a estrutura objetiva da atividade. Na mente humana há, portanto, uma relação indireta, mediatizada, entre o conteúdo da ação e o motivo desta. Usando os termos de Leontiev, ao conteúdo da ação, isto é, àquilo que constitui seu objeto, vincula-se o "significado da ação", ou seja, o significado da ação é aquilo que o sujeito faz, é a resposta à pergunta: $O$ que o indivíduo está fazendo? Mas a consciência humana, segundo Leontiev, trabalha com as relações entre o significado e o sentido da ação. O que seria o sentido da ação? Para Leontiev o sentido da ação é dado por aquilo que liga, na consciência do sujeito, o objeto de sua ação (seu conteúdo) ao motivo dessa ação.
\end{abstract}

Para este autor, a consciência do indivíduo efetiva-se pela sua participação ativa no processo formativo promovendo, assim, um ensino que alavanque a aprendizagem e, consequentemente, o desenvolvimento dos sujeitos.

Desta forma, faz-se necessário o acesso das pessoas público-alvo da educação especial à educação regular, prioritariamente, por dois motivos. Primeiro, porque tal acesso condiz com a sua condição de pessoa, independentemente das circunstâncias físicas, mentais, sensoriais e/ou sociais; segundo, porque o acesso à escola e aos conhecimentos sistematizados na Ciência, na Arte, na Filosofia contribui, significativamente, para a formação do ser humano integral ${ }^{11}$ e, assim, promove, efetivamente, a humanização dos sujeitos. É Saviani (2013b, p. 247) quem adverte-nos sobre tal feito:

\footnotetext{
Mas por que é necessário produzir, em cada indivíduo, a humanidade? Isso é necessário porque a criança não nasce já com as características que definem o ser humano. Para que ela se constitua como homem, exige-se a intervenção dos seres humanos já constituídos como homens, especificamente dos adultos.
} 
http://dx.doi.org/10.5902/1984686X41161

E ainda:

O homem é, pois, um produto da educação. Portanto, é pela mediação dos adultos que num tempo surpreendentemente muito curto a criança se apropria das forças essenciais humanas objetivadas pela humanidade tornando-se, assim, um ser revestido das características humanas incorporadas à sociedade na qual dela nasceu. (SAVIANI, 2013b, p. 250).

Objetivando que melhor compreenda-se a teoria pedagógica histórico-crítica, Saviani (2013, p. 76), assim, define-a:

Em outros termos, o que eu quero traduzir com a expressão pedagogia histórico-crítica é o empenho em compreender a questão educacional com base no desenvolvimento histórico objetivo. Portanto, a concepção pressuposta nesta visão da pedagogia histórico-crítica é o materialismo histórico, ou seja, a compreensão da história a partir do desenvolvimento material, da determinação das condições materiais da existência humana.

Fundamentando-se nesta teoria, o direito à educação é revestido de um caráter pedagógico defendendo não só o acesso de todos(as) as pessoas à instituição escolar, mas, acima de tudo, preconizando a transformação concreta dessa forma escolar marcadamente elitista e excludente em uma outra, efetivamente humana, igualitária e emancipadora.

Nesse sentido, podemos afirmar que a pedagogia histórico-crítica compartilha do pressuposto da educação inclusiva para a qual a base da exclusão, do preconceito e da estigmatização é social e não individual. Cabe, portanto, à comunidade escolar (trans)formar todas as condições que impedem a acessibilidade e o pleno desenvolvimento, em todas as dimensões, das pessoas com deficiência.

\section{Humanização, direito à educação, escolarização}

Ao refletirmos sobre a história da educação especial, tomando como base os preceitos da pedagogia histórico-crítica, notamos que, efetivamente, presenciamos, nas últimas décadas, de um aumento do acesso das pessoas com deficiência à instituição escolar. De acordo com Silva (2014, p. 80-81),

(...) nos últimos 30 anos, a política de "integração escolar" provocou a expansão das classes especiais na escola pública, mas ao mesmo tempo favoreceu o processo de exclusão na escola regular. Já nos últimos 15 anos (aproximadamente), as classes especiais e as escolas especiais privadas e filantrópicas vêm sendo substituídas pelas salas de recursos (atual sala de atendimento educacional especializado), porém de modo precário, visto que boa parte dos alunos com necessidades especiais, inserida nas salas de aula da escola regular, está sem receber nenhum tipo de suporte para a escolarização. E isso produziu o fenômeno que Freitas (2002) intitulou de "inclusão-excludente" para se referir à lógica perversa escondida nas políticas de universalização da educação básica, que recorrem à progressão continuada e aos ciclos de escolarização. 
http://dx.doi.org/10.5902/1984686X41161

Isso implica afirmar que, mesmo que do ponto de vista jurídico o direito à educação esteja sendo garantido aos alunos público-alvo da educação especial, a garantia de matrícula não se reverte, necessariamente, em garantia de aprendizagem e, consequentemente, desenvolvimento (SILVA, 2014).

Nessa mesma linha argumentativa, Garcia e Michels (2011, p. 115) afirmam que

A organização da política de Educação Especial nos últimos anos pode ser caracterizada como uma "política de resultados", ou seja, um privilegiamento de efeitos que mostrem vantagens na relação custo/benefício tais como maior número de alunos matriculados na relação com os investimentos financeiros. Tais resultados são constitutivos de uma gestão gerencial articulada à racionalização das atividades estatais e que não se atém a uma análise mais qualitativa da educação. Essa concepção de gestão implica uma tentativa de imposição do próprio processo de implantação da política quando define quais são as tarefas locais e como devem ser desenvolvidas.

Martins (2013a) ajuda-nos a avançar na compreensão desse processo de "inclusãoexclusão" a que estão submetidos os alunos público-alvo da educação especial ao trazer à baila a problemática do processo de humanização. Segundo Martins (2013a, p. 131-132):

\begin{abstract}
Verifica-se que a humanidade não "nasce" nas pessoas a partir delas mesmas, mas resulta da humanidade objetivada e disponibilizada às suas apropriações e, coadunando-se a esse fato, tanto a psicologia históricocultural quanto a pedagogia histórico-crítica voltam-se à análise das condições objetivadas que, em uma sociedade de classes, reservam condições desiguais de humanização para diferentes indivíduos.

É no âmbito da socialização dos produtos do trabalho imaterial, isto é, do trabalho de decodificação abstrata da realidade concreta, que a educação escolar desponta como um processo a quem compete oportunizar a apropriação dos conhecimentos historicamente sistematizados e, ao fazê-lo, corroborar o enriquecimento do universo de significações instituinte da consciência dos indivíduos.
\end{abstract}

Decorre disso a necessidade de que a educação escolar seja oportunizada para o desenvolvimento da pessoa como forma de humanização integral e não se realizando apenas com o acesso dos indivíduos à escola, não bastando passar pela escola sem que se tenham aprendizagens que gerem desenvolvimento efetivo.

Destarte, para o público-alvo da educação especial, o direito à educação é cercado por obstáculos, ora pela falta de conhecimento das possibilidades de aprendizagem e desenvolvimento destes, ora pela falta de informações sobre as deficiências e transtornos, de certa forma até mesmo pelo descumprimento do que reza a legislação em relação à aprendizagem para o desenvolvimento dos indivíduos ${ }^{12}$.

Ao tratarmos das possibilidades de aprendizagem, em uma sociedade que almeja resultados imediatos, as vivências de escolarização parecem ser fundadas na premissa da 
http://dx.doi.org/10.5902/1984686X41161

não capacidade da pessoa com deficiência, olhando mais para a condição do sujeito do que para o que pode e deve ser oportunizado através da educação.

No entanto, como garantir aos indivíduos com comprometimento intelectual, àqueles que fogem do padrão da normalidade quanto ao comportamento, ou aos indivíduos com comprometimento motor e cognitivos graves o acesso e a apropriação aos conhecimentos sistematizados? Como oportunizar aos professores uma formação sólida que possibilite 0 ensino destes sujeitos?

Para Barroco (2011, p. 173) fundamentando-se em Vygotsky ${ }^{13}$ e Luria:

o biológico deve ser superado pelo cultural. Ou ainda, estava em pauta a defesa de que, quando falta o talento biológico, deve ser formado o talento cultural. Dito isso de outro modo, as pessoas com deficiência, mesmo tendo grandes especificidades em seus desenvolvimentos, podem e devem frequentar a escola, e o que esta lhes ensina deve projetá-las para outro patamar, deve transformá-las, metamorfoseá-las, deve contribuir para que passem de crisálidas a borboletas.

Ainda na esteira dessa reflexão, faz-se necessário conhecer o sujeito a ser educado, a necessidade de cada ser, pois, de acordo com Martins (2013b, p. 297), "a tríade formaconteúdo-destinatário se impõe como exigência primeira no planejamento de ensino. Como tal, nenhum desses elementos, esvaziados das conexões que os vinculam podem, de fato, orientar o trabalho pedagógico".

Ao conhecer o sujeito, dominar os conteúdos-objeto de ensino e aprendizagem e definir as formas mais adequadas para sua transmissão-apropriação, percebemos que, mesmo o educando sendo considerado um sujeito ativo desse processo, também o professor ocupa um papel relevante na elaboração e na gestão do processo de trabalho educativo.

Marsiglia, Martins e Lavoura (2019, p.18) ajudam-nos a aprofundar nossas reflexões, ao afirmarem que

As formas pedagógicas adequadas são todas aquelas que contribuam para a transmissão do saber escolar. Em didática, isso se refere aos procedimentos, recursos e técnicas que permitem a efetivação dos conteúdos levando em conta os sujeitos a que se destinam, sempre carregados de uma concepção de mundo que se pretende transmitir. Vale dizer ainda que esse processo precisa ser avaliado, de modo a garantir tanto o replanejamento das ações pedagógicas (quando necessário) quanto os novos planejamentos, para que o ensino se efetive de forma cada vez mais complexa. Aí estão, pois, os temas fundamentais da didática - planejamento, objetivos educacionais, conteúdos, métodos e avaliação. 
http://dx.doi.org/10.5902/1984686X41161

Entendemos que, quando o professor organiza o processo de trabalho educativo, de certa forma, o direito à educação também está sendo garantido, já que a síntese do que foi produzido na cultura dos homens é reproduzido em cada indivíduo independentemente das suas condições de pessoas com deficiência ou não.

Assim, também se faz necessário ao professor buscar elementos que o instrumentalize teórica e praticamente, pois, no trabalho educativo que vise garantir a concreticidade do direito à educação, é imprescindível a este profissional criar os motivos da aprendizagem, gerar novas necessidades de compreensão acerca do real, para além da imediaticidade da vida e das práticas cotidianas (MARSIGLIA, MARTINS e LAVOURA, 2019, p. 16).

Logo, nas palavras de Saviani ${ }^{14}$ (apud MARSIGLIA, MARTINS e LAVOURA, 2019, p. 16):

É nesse quadro que cabe ao professor se perguntar então o que é importante para os alunos aprenderem [...] para viver nessa sociedade e participar ativamente dela e na medida em que essa sociedade é detectada como insatisfatória para o atendimento das necessidades humanas, o que é necessário os alunos aprenderem para agir nessa sociedade buscando transformá-la, superá-la na direção de uma forma social mais adequada às necessidades humanas.

Daí a garantia do direito à educação no sentido que buscamos, aqui, defender, pois, na sociedade capitalista, marcadamente desigual e excludente, tal educação é oferecida no sentido de normalizar, fazer com que os sujeitos tornem-se o mais próximo da normalidade, com a visão de que estes devem produzir e consumir para colaborar com o desenvolvimento da sociedade. Assim, é fulcral "a aceitação da escola regular pública como espaço não só de direito, mas também como o local mais adequado para a escolarização dos alunos com deficiência" (JANNUZZI e CAIADO, 2013, p. 3).

Portanto, para a pedagogia histórico-crítica, faz-se necessário o pleito ao direito à educação, concretamente efetivado, de todas as pessoas e, neste grupo, as pessoas com deficiência, pois o acesso aos conhecimentos historicamente sistematizados fazem com que os sujeitos desvelem a realidade que está posta e, com isso, possam lutar, coletivamente, por uma outra formação societária.

Marsiglia, Martins e Lavoura (2019, p. 7) asseveram, nesse sentido, que "a educação deve se comprometer com a elevação da consciência como parte fundamental da transformação social". Para que tal situação aconteça, é necessário a compreensão da educação como mediação ${ }^{15}$ da prática social. É através da educação escolar que é possível garantir aos indivíduos o desenvolvimento das suas potencialidades para a transformação da 
prática social. Seguindo a esteira de pensamento destes autores, entendemos que "oferecer aos educandos os conteúdos escolares mais desenvolvidos significa dar-lhes os instrumentos de compreensão da realidade" (MARSIGLIA, MARTINS e LAVOURA, 2019, p. 18).

Considerando que estar na escola não é condição de apropriação dos conhecimentos teórico-práticos necessários à efetiva inserção e participação social, faz-se necessário que a organização do processo de trabalho pedagógico tenha sempre essa finalidade como horizonte, pois, como aqui buscamos defender, significa a concretude do direito à educação. Em relação aos alunos público-alvo da educação especial, o primeiro desafio consiste em garantir todas as condições necessárias para que se apropriem e façam uso social do sistema alfabético de escrita, condição primeira para o acesso aos saberes das diferentes áreas do saber, bem como da vida social como um todo. A alfabetização, nessa perspectiva, participa da concretude do direito à educação, bem como outros aspectos da cultura humana.

Considerando que para Jannuzzi e Caiado (2013, p. 64):

Assim, temos de levar-Ihes todo o conhecimento sistematizado, a começar pela alfabetização, usando métodos, técnicas e procedimentos adequados ao ensino, garantindo formação criadora para o mundo do trabalho. Trata-se de um projeto de educação escrito na utopia, enquanto um amanhã possível.

\section{Considerações finais}

Em suma, para além das legislações e do acesso (matrícula) na escola regular, a pedagogia histórico-crítica defende a socialização dos conhecimentos historicamente produzidos pela humanidade como papel da escola no sentido do direito à educação. Como afirma Saviani (2013, p. 17), “ora, clássico na escola é a transmissão-assimilação do saber sistematizado. Este é o fim a atingir. É aí que cabe encontrar a fonte natural para elaborar os métodos e as formas de organização do conjunto de atividades da escola, isto é, do currículo".

Portanto, se aos alunos não é garantido o acesso ao conhecimento elaborado na cultura dos homens, o direito à educação é negado, sendo a escola o lócus para que os conhecimentos científicos, artísticos, filosóficos e éticos, sejam oportunizados de forma sistematizada. Neste caso, se tratando dos alunos público-alvo da educação especial, cada um conforme as suas condições biofísicas, psíquicas e sociais, se desenvolverá dentro das suas potencialidades e possibilidades, sendo o processo do trabalho educativo, objetivar a aprendizagem como uma finalidade, a atingir. 
http://dx.doi.org/10.5902/1984686X41161

Quanto aos professores, ainda que em condições precárias para desenvolver o trabalho educativo, cabe o dever ético-político de buscar, nos aportes teórico-práticos das concepções pedagógicas contra-hegemônicas, os fundamentos que thes possibilitem a materialização de uma educação transformadora.

\section{Referências}

BARROCO, Sonia Mari Shima. Pedagogia histórico-crítica, psicologia histórico-cultural e educação especial: em defesa do desenvolvimento da pessoa com e sem deficiência. In: MARSIGLIA, Ana Carolina Galvão (org.). Pedagogia histórico-crítica: 30 anos. Campinas/SP: Autores Associados, 2011. (Coleção memória da educação). p. 169-196.

BRASIL. Lei n. 4.024, de 20 de dezembro de 1961. Fixa as Diretrizes e Bases da Educação Nacional. Disponível em: http://wwwp.fc.unesp.br/ lizanata/LDB\%20402461.pdf. Acesso em: jun./2019.

BRASIL. Senado Federal. Constituição Federal de 1988. Brasília: Presidência da República, 1988. 498p. Disponível em: https://www2.camara.leg.br/atividadelegislativa/legislacao/constituicao1988/arquivos/ConstituicaoTextoAtualizado_EC\%20105. pdf. Acesso em: 16/06/2020.

BRASIL. Decreto № 5.626, de 22 de novembro de 2005. Regulamenta a Lei № 10.436, de 24 de abril de 2002, que dispõe sobre a Língua Brasileira de Sinais - Libras, e o art. 18 da Lei $n^{\circ}$ 10.098, de 19 de dezembro de 2000 . Disponível em: https://www.planalto.gov.br/ccivil_03/_ato2004-2006/2005/decreto/d5626.htm. Acesso em: $15 / 06 / 2020$.

BRASIL. Resolução no 4, de 2 de outubro de 2009. Institui Diretrizes Operacionais para - Atendimento Educacional Especializado na Educação Básica, modalidade Educação Especial. Disponível em: http://portal.mec.gov.br/dmdocuments/rceb004_09.pdf. Acesso em: 21/05/2019.

BRASIL. Decreto no 7.611, de 17 de novembro de 2011. Dispõe sobre a educação especial, o atendimento educacional especializado e dá outras providências. Disponível em: http://www.planalto.gov.br/ccivil_03/_Ato2011-2014/2011/Decreto/D7611.htm\#art11. Acesso em: 06/05/2019.

CAIADO, Kátia Regina Moreno; BAPTISTA, Cláudio Roberto; JESUS, Denise Meyrelles (Orgs.). Deficiência Mental e Deficiência Intelectual em Debate. Uberlândia: Navegando Publicações, 2017.

DUARTE, Newton. Formação do indivíduo, consciência e alienação: o ser humano na psicologia de A. N. Leontiev. Cad. CEDES, Campinas, v. 24, n. 62, p. 44-63, abril de 2004. Disponível em http://www.scielo.br/scielo.php?script=sci_arttext\&pid=S0101$32622004000100004 \&$ Ing=en\&nrm=iso. Acesso em jul./ 2019. 
DUARTE, Newton. A liberdade na pedagogia histórico-crítica e o currículo escolar. In DUARTE, Newton. Os conteúdos escolares e a ressurreição dos mortos: contribuição à teoria histórico-crítica do currículo. Campinas/SP: Autores Associados, 2016. (Coleção educação contemporânea), p. 120-141.

GARCIA, Rosalba Maria Cardoso; MICHELS, Maria Helena. A política de educação especial no Brasil (1991- 2011): uma análise da produção do GT 15 - educação especial da ANPED. Rev. Bras. Ed. Esp., Marília, v.17, Maio-Ago. 2011. Edição Especial. p. 105123.

GOFFREDO, Vera Flôr Sénechal de. Fundamentos da educação especial. Rio de Janeiro: UNIRIO/CEAD, 2007. 158p.

JANNUZZI, Gilberta de Martino. A educação do deficiente no Brasil: dos primórdios ao início do século XXI. 3 ed. rev. Campinas/SP: Autores Associados, 2012. (Coleção educação contemporânea), $211 \mathrm{p}$.

JANNUZZI, Gilberta de Martinho; CAIADO, Katia Regina Moreno. APAE: 1954 - 2011 algumas reflexões. Campinas/SP: Autores Associados, 2013. (Coleção educação contemporânea), 72p.

MAIOR, Isabel. Breve trajetória histórica do movimento das pessoas com deficiência. São Paulo: Secretaria de Estado dos Direitos da Pessoa com Deficiência, 2015.

MARSIGLIA, Ana Carolina Galvão; MARTINS, Lígia Márcia; LAVOURA, Tiago Nícola. Rumo à outra didática histórico-crítica: superando imediatismos, logicismos formais e outros reducionismos do método dialético. Revista HISTEDBR On-line, Campinas, SP, v.19, s/n, p. 1-28, mar./2019. Disponível em: https://periodicos.sbu.unicamp.br/ojs/index.php/histedbr/issue/view/1587. Acesso em: mai./2019.

MARTINS, Lígia Márcia. Os fundamentos psicológicos da pedagogia histórico-crítica e os fundamentos pedagógicos da psicologia histórico-cultural. Germinal: Marxismo e Educação em Debate, Salvador, v.5, n.2, p. 130-143, dez. 2013a. Disponível em: https://portalseer.ufba.br/index.php/revistagerminal/article/view/9705. Acesso em: mar./ 2016.

MARTINS, Lígia Márcia. O desenvolvimento do psiquismo e a educação escolar: contribuições à luz da psicologia histórico-cultural e da pedagogia histórico-crítica. Campinas/SP: Autores Associados, 2013b. 319p.

MARTINS, Marcos Francisco. Marx e Engels: apontamentos sobre educação. Comunicações, Piracicaba, v. 24, n. 2, p. 247-266, mai. - ago./2017. Disponível em: file:///C:/Users/Usuario/Downloads/Marx_e_Engels_apontamentos_sobre_educacao_e_en sino.pdf. Acesso em jul./2018.

OLIVEIRA, Dalila Andrade; VIEIRA, Livia Fraga. Trabalho na Educação Básica: a condição docente em sete estados brasileiros. Belo Horizonte, MG: Fino Traço, 2012. 
SAVIANI, Dermeval. Sobre a natureza e especificidade da educação. In: SAVIANI, Dermeval. Pedagogia histórico-crítica: primeiras aproximações. 11 ed. rev. Campinas / SP: Autores Associados, 2013a. p. 11- 20.

SAVIANI, Dermeval. Infância e pedagogia histórico-crítica. In: MARSIGLIA, Ana Carolina Galvão (Org.). Infância e pedagogia histórico-crítica. Campinas / SP: Autores Associados, 2013b. p. 247-280.

SAVIANI, Dermeval. O conceito dialético de mediação na pedagogia histórico-crítica em intermediação com a psicologia histórico-cultural. Germinal: Marxismo e Educação em Debate, Salvador, v.7, n.1, p. 26-43, jun. 2015. Disponível em: https://portalseer.ufba.br/index.php/revistagerminal/issue/view/1004/showToc. Acesso em: dez./2018.

SAVIANI, Dermeval. Escola e democracia I: a teoria da curvatura da vara. In SAVIANI, Dermeval. Escola e democracia. 43 ed. rev. Campinas/SP: Autores Associados, 2018. p. 29-46.

SILVA, Régis Henrique dos Reis. Contribuições da Pedagogia Histórico-crítica para a Educação Especial Brasileira. Revista Histedbr On-line, Campinas, número 58, p. 78-89, set 2014. Disponível em: https://periodicos.sbu.unicamp.br/ojs/index.php/histedbr/article/view/8640380/7939. Acesso em: 17/08/2020.

SOUSA, Joceli de Fátima Arruda. Referencial teórico e formação de professores: uma análise necessária. In: MATOS, Neide da Silveira Duarte de; SOUSA, Joceli de Fátima Arruda; SILVA, João Carlos da. Pedagogia histórico-crítica: revolução e formação de professores. Campinas/SP: Autores Associados, 2018. p. 37-51.

TEIXEIRA, Maria Cristina. O direito à educação nas constituições brasileiras. Revista da faculdade de Direito, v.5, n.5, p. 146-168, 2008 . Disponível em: https://www.metodista.br/revistas/revistas-ims/index.php/RFD/issue/view/47. Acesso em jun./2019.

VYGOTSKY, Lev Semyonovich; LURIA, Alexander Romanovich. Estudos sobre a história do comportamento: símios, homem primitivo e criança. Trad. de Lolio Lourenço de Oliveira. Porto Alegre, Artes Médicas, 1996.

\section{Notas}

1 De acordo com a Resolução ํㅜ 4, de 2 de outubro de 2009, considera-se público-alvo: I. Alunos com deficiência: aqueles que têm impedimentos de longo prazo de natureza física, intelectual, mental ou sensorial, os quais, em interação com diversas barreiras, podem obstruir sua participação plena e efetiva na sociedade em igualdade de condições com as demais pessoas. II. Alunos com transtornos globais do desenvolvimento: aqueles que apresentam um quadro de alterações no desenvolvimento neuropsicomotor, comprometimento nas relações sociais, na comunicação ou estereotipias motoras. Incluem-se nessa definição alunos com autismo clássico, síndrome de Asperger, síndrome de Rett, transtorno desintegrativo da infância (psicoses) e transtornos invasivos sem outra especificação. III. Alunos com altas habilidades/superdotação: aqueles que apresentam um potencial elevado e grande envolvimento com as áreas do conhecimento humano, isoladas ou combinadas: intelectual, acadêmica, liderança, psicomotora, artes e criatividade. (BRASIL, 2009). Disponível em: http://portal.mec.gov.br/dmdocuments/rceb004_09.pdf. Acesso em: 21/05/2019. 
2 Segundo o observatório do PNE (Plano Nacional de Educação), o próprio acompanhamento das metas do PNE em relação aos educandos com deficiência é difícil de se fazer em função dos dados coletados. Os dados de matrícula do Censo Escolar tem sido objeto de vários trabalhos em relação à inclusão das pessoas com deficiência apontando um aumento significativo no número de matrículas. Contudo, perguntas têm sido feitas em relação à garantia efetiva do direito à educação em que, por exemplo a respeito dos alunos com deficiência intelectual, "destacam-se alguns questionamentos que permanecem ao problematizarmos o alto número de matrículas de alunos cadastrados como deficientes intelectuais no Censo Escolar do Estado de São Paulo. O conceito de deficiência intelectual adotado enquanto uma limitação significativa no funcionamento intelectual e no comportamento adaptativo não favorece o encaminhamento dos alunos oriundos do fracasso escolar? A quem favorece a manutenção histórica das instituições especializadas de caráter privado e filantrópico? Quem faz e como são realizadas as avaliações pedagógicas dos alunos das classes regidas por professor especializado para recomendar a permanência ou encaminhamento para a classe regular? Quem faz e como são realizadas as avaliações pedagógicas dos alunos matriculados nas escolas conveniadas e credenciadas para o ingresso ou retorno à escola comum? (CAIADO et al, 2017, p. 37-38).

${ }^{3}$ Neste sentido, ler o livro de Gilberta de Martino Jannuzzi, citado na referência deste texto.

${ }^{4} \mathrm{~A}$ este respeito ler o texto desta autora na íntegra. TEIXEIRA, Maria Cristina. O direito à educação nas constituições brasileiras. Disponível em:

ims/index.php/RFD/issue/view/47. Acesso em: 30/06/2019.

${ }^{5}$ De acordo com o Decreto no 7.611, de 17 de novembro de 2011, em seu artigo $5^{\circ}$, $\S 3^{\circ}$, "As salas de recursos multifuncionais são ambientes dotados de equipamentos, mobiliários e materiais didáticos e pedagógicos para a oferta do atendimento educacional especializado". Disponível em: http://www.planalto.gov.br/ccivil_03/_Ato2011-2014/2011/Decreto/D7611.htm\#art11. Acesso em: 06/05/2019.

${ }^{6}$ Decreto № 5.626, de 22 de novembro de 2005. Regulamenta a Lei oㅜ 10.436, de 24 de abril de 2002, que dispõe sobre a Língua Brasileira de Sinais - Libras, e o art. 18 da Lei no 10.098, de 19 de dezembro de 2000. Disponível em: https://www.planalto.gov.br/ccivil_03/_ato2004-2006/2005/decreto/d5626.htm. Acesso em: 15/06/2020.

${ }^{7}$ No Brasil, tal movimento tem início no final dos anos 1970 e se intensifica nos anos 1980. A esse respeito ler LANNA JÚNIOR, Mário Cléber Martins (Comp.). História do Movimento Político das Pessoas com Deficiência no Brasil. - Brasília: Secretaria de Direitos Humanos. Secretaria Nacional de Promoção dos Direitos da Pessoa com Deficiência, 2010. p. 30-35. Disponível em: http://www.portalinclusivo.ce.gov.br/phocadownload/publicacoesdeficiente/historia\%20movimento\%20politic ०\%20pcd\%20brasil.pdf. Acessado em: 30/04/2019.

8 De acordo com Maior (2015), o processo de luta pela inclusão tem seguido um longo caminho que, ao vencer o preconceito e exclusão, vai da tutela à autonomia das pessoas com deficiência. Esse processo tem sido pautado pela tentativa de superação de uma perspectiva biomédica, fundada no indivíduo com deficiência, para uma abordagem social, em que se luta pela mudança das condições sociais que geram a exclusão e estigmatização.

${ }^{9}$ ENGELS, F. Anti-Duhring. 2. ed. Rio de Janeiro: Paz e Terra, 1979.

10 Para melhor compreensão ler: DUARTE, Newton. Formação do indivíduo, consciência e alienação: o ser humano na psicologia de A. N. Leontiev. Cad. CEDES, Campinas, v. 24, n. 62, p. 44-63, abril de 2004. Disponível em http://www.scielo.br/scielo.php?script=sci_arttext\&pid=S010132622004000100004\&lng=en\&nrm=iso. Acessado em: 22/07/2019.

${ }^{11}$ Ainda de acordo com a formação do ser humano integral, Martins (2017, p. 262), ao citar Gramsci assevera que: "Na verdade, Gramsci cunhou um conceito-chave para a interpretação do legado filosófico, ético-politico e cultural que deixou e que identifica a proposta educativa que formulou: unitário. Com ele foi possível a Gramsci manifestar-se acerca da proposta educativa que formulou e que considerava ortodoxa em relação ao marxismo originário: formação unitária e, por decorrência, escola unitária. Assim, o autor indicou a necessária articulação entre saber e fazer no processo educativo escolar, para possibilitar aos subalternos a apropriação do patrimônio cultural da humanidade sintetizado na forma de ciência, filosofia e arte, o que na terminologia da Pedagogia Histórico-Crítica formulada por Saviani, que tem Gramsci como uma das principais referências, é identificado por "clássicos". Além disso, o termo unitário refere-se também a uma crítica propositiva à educação orientada pela perspectiva burguesa, pois no mesmo tempo em que se recusa a 
http://dx.doi.org/10.5902/1984686X41161

diferenciação nos sistemas de ensino capitalista, justificadas a partir de diferenças naturais e aptidões pessoais, defende-se uma única escola para todos. Ou seja, está presente na formulação gramsciana a necessidade de as classes subalternas dominarem o que a classe dominante domina, para construir um novo padrão de sociabilidade não burguesa, uma nova civilização, o socialismo.

12 Segundo o artigo Art. 206. O ensino será ministrado com base nos seguintes princípios: I - igualdade de condições para o acesso e permanência na escola (BRASIL, 1988). Disponível em: https://www2.camara.leg.br/atividade-

legislativa/legislacao/constituicao1988/arquivos/ConstituicaoTextoAtualizado_EC\%20105.pdf. Acesso em $16 / 06 / 2020$.

${ }^{13}$ A grafia do nome está de acordo com a citada no texto da autora, do qual foi tirada a citação. VYGOTSKY, L. S.; LURIA, A.R. Estudos sobre a história do comportamento: símios, homem primitivo e criança. Trad. de Lólio Lourenço de Oliveira. Porto Alegre, Artes Médicas, 1996.

14 SAVIANI, D. Conferência de encerramento. Congresso "Infância e pedagogia histórico-crítica". Vitória, ES: Universidade Federal do Espírito Santo, 2012b. Gravação sonora.

${ }_{15}$ Para estes autores: "Afirmar que a educação é uma atividade mediadora da prática social significa que ela cumpre o papel de promover o máximo desenvolvimento das capacidades afetivo-cognitivas dos indivíduos, dando-Ihes condição para a transformação social. A pedagogia histórico-crítica não dá à educação o poder de transformação social direta (por isso ela é mediadora) e nem às consciências uma operacionalidade autônoma e independente das estruturas sociais. Por isso, para a pedagogia histórico-crítica, a educação deve se comprometer com a elevação da consciência como parte fundamental da transformação social". Ler: MARSIGLIA, Ana Carolina Galvão; MARTINS, Lígia Márcia; LAVOURA, Tiago Nícola. Rumo à outra didática histórico-crítica: superando imediatismos, logicismos formais e outros reducionismos do método dialético. Revista HISTEDBR On-line, Campinas, SP, v.19, s/n, p. 1-28, mar./2019. Disponível em: https://periodicos.sbu.unicamp.br/ojs/index.php/histedbr/issue/view/1587. Acesso em: 04/05/2019.

\section{Correspondência}

Adriana Cristina Morais Eloy - Rodovia João Leme dos Santos, km 110, SP-264, Sorocaba, São Paulo -- Brasil

CEP: $18052-780$

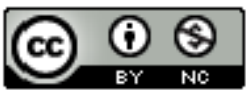

This work is licensed under a Creative Commons Attribution-NonCommercial 4.0 International (CC BY-NC 4.0) 